\title{
WILLIAM JAMES E CARL GUSTAV JUNG NA CONFERÊNCIA EM CLARK: REPERCUSSÕES TEÓRICAS
}

\author{
WILLIAM JAMES AND CARL GUSTAV JUNG IN THE CONFERENCE AT CLARK: THEORETICAL \\ REPERCUSSIONS
}
WILLIAM JAMES Y CARL GUSTAV JUNG EN LA CONFERENCIA DE CLARK: REPERCUSIONES TEÓRICAS

\author{
Pedro Henrique Costa de Resende* \\ Walter Melo ${ }^{* *}$
}

\begin{abstract}
RESUMO
A obra de Carl Gustav Jung ainda é pouco pesquisada no contexto acadêmico. Devido à escassez de estudos sobre a fundamentação teórica do referido autor, muitos consideram seu trabalho como influenciado somente pela psicanálise freudiana. No entanto o próprio Jung, ao longo de suas obras coligidas, destaca a figura de William James como o autor que mais o incentivou em suas pesquisas. Em 1909, ainda inserido no movimento psicanalítico, o autor suíço viaja para a América, onde apresenta, na Conferência da Universidade de Clark, seu conhecido estudo sobre associações de palavras. $\mathrm{Na}$ referida conferência, Jung conhece William James. A partir desse encontro histórico, as referências ao pensador americano se intensificam. O objetivo desse trabalho é destacar os principais temas da teoria jameseana que repercutem significativamente sobre a psicologia de C. G. Jung, especialmente, seus estudos psiquiátricos, sua avaliação do pragmatismo, sua teoria do inconsciente, teoria das emoções e experiência religiosa.
\end{abstract}

Palavras-chave: Carl Gustav Jung. William James. Psicologia analítica.

\begin{abstract}
The work of Carl Gustav Jung is still poorly researched in the academic context. Due to the lack of studies on the author's theoretical foundation, many consider his work as influenced only by Freudian psychoanalysis. However, Jung himself, along his collected works, points the figure of William James as the author who most encouraged him in his researches.
\end{abstract}

\footnotetext{
Texto recebido em 6 de outubro de 2015 e aprovado para publicação em 15 de setembro de 2016.

Doutorando no Programa de Pós-Graduação em Psicologia da Universidade Federal de Juiz de Fora (PPGPSI/UFJF), mestre em Psicologia pela Universidade Federal de São João del Rei (UFSJ), graduado em Filosofia e Psicologia pela UFSJ. Endereço: Avenida Trinta e Um de Março, 752 - Colônia do Marçal, São João del-Rei - MG, Brasil. CEP: 36302-016: Telefone: (55) (32) 991308698. E-mail: heloim@mgconecta.com.br.

** Professor Associado II no Departamento de Psicologia da UFSJ, docente no PPGPSI/UFSJ. Endereço: Rua Idilberto de Andrade, 261 - Cascalho, Tiradentes-MG, Brasil. CEP: 36325-000.E-mail: wmelojr@gmail.com.
} 
In 1909, still inserted in the psychoanalytic movement, the Swiss author travels to America, where he presents, in the Clark University Conference, his well-known study of word associations. In this conference, Jung meets William James. From that historic meeting the references to the American thinker intensify. The aim of this study is to highlight the main themes of Jamesian theory that impact significantly on the C. G. Jung's psychology, especially his psychiatric studies, review of pragmatism, his theory of the unconscious, theory of emotions and religious experience.

Keywords: Carl Gustav Jung. William James. Analytical Psychology.

\section{RESUMEN}

La obra de Carl Gustav Jung es poco investigada en el contexto académico. Debido a la falta de estudios sobre el fundamento teórico de este autor, muchos consideran su trabajo como influenciado solamente por el psicoanálisis de Freud. Sin embargo, el propio Jung, en sus obras completas, enfatiza la figura de William James como el autor que más le animó en sus investigaciones. En 1909, aún insertado en el movimiento psicoanalítico, el autor suizo viaja a Estados Unidos donde presenta, en la Conferencia de la Universidad de Clark, su conocido estudio de asociaciones de palabras. En esta conferencia, Jung conoce a William James. A partir de este encuentro histórico, las referencias al pensador americano se intensifican. El objetivo de este trabajo es poner de relieve los principales temas de la teoría jameseana que inciden significativamente en la psicología de C. G. Jung, en especial, sus estudios psiquiátricos, su revisión del pragmatismo, su teoría del inconsciente, la teoría de las emociones y la experiencia religiosa.

Palabras clave: Carl Gustav Jung. William James. Psicología analítica.

\section{INTRODUÇÃO}

W illiam James e Carl Gustav Jung participaram de contextos históricos e sociais distintos. Em 1909, os dois autores se encontraram pela primeira vez na conferência realizada na Universidade de Clark, nos Estados Unidos. Duas conversas se seguiram, com repercussões na obra do autor suíço. $\mathrm{Na}$ época, a importância de James nos campos da Psicologia, Filosofia e Religião já era confirmada por suas obras: The principles of Psychology (1890b); The varieties of religious experience (1902); e Pragmatism (1907b). Obras que expunham a variedade de interesses do autor assim como sua tentativa abrangente de criar uma ciência da mente. Por outro lado, Jung era ainda um jovem médico participante do nascente movimento psicanalítico, sendo o mais novo palestrante presente na conferência em Clark. Seu convite era motivado por suas experiências bem- 
sucedidas com o teste de associação de palavras. $\mathrm{Na}$ época, ainda não havia publicado seus estudos mais importantes sobre o inconsciente coletivo, tipologia e religião, que o levariam, posteriormente, a ser reconhecido mundialmente (Bair, 2003; Richardson, 2006; Sech, Araújo \& Moreira-Almeida, 2013).

A Conferência na Universidade de Clark fez parte das comemorações pelos seus 20 anos de fundação. Para celebrar a data, Granville Stanley Hall, presidente da instituição, organizou uma série de conferências, concentradas, principalmente, nos meses de julho e setembro. As conferências abordaram temas referentes às principais áreas de estudo desenvolvidas na Universidade de Clark. Durante cinco dias de julho, o bem-estar da criança foi debatido por diversos palestrantes, de diferentes campos do conhecimento. No outono de 1909, ocorreu o debate de maior relevância, com a presença do antropólogo Franz Boas, do físico e químico Ernest Rutheford e de Albert Abraham Michelson, o primeiro americano a ganhar um prêmio Nobel em Ciência, além de Freud e de Jung. ${ }^{1}$ Freud apresentou trabalhos sobre as noções básicas de sua nova teoria psicológica, posteriormente publicadas como Cinco lições de psicanálise, e Jung abordou as pesquisas que desenvolveu com o teste de associação de palavras no Hospital Burghölzli, além de um estudo sobre Psicologia infantil (Koelsch, 1984).

Essa foi a primeira viagem do grupo psicanalítico ao chamado Novo Continente. Além de Freud e Jung, a comitiva psicanalítica contou com a presença de Sándor Ferenczi, que integrou o grupo que partiu de Bremen, na Alemanha, no dia 21 de agosto, ${ }^{2}$ no vapor George Washington. Após oito dias de viagem, chegaram a Hoboken, Nova Jersey, seguindo diretamente para Nova Iorque, onde o trio se reuniu a Ernest Jones e a Abraham Arden Brill. ${ }^{3}$ Após visitarem a cidade, a comitiva seguiu, no dia 5 de setembro, para Worcester, onde se localiza a Universidade de Clark.

A apresentação de Freud foi dividida em cinco palestras, proferidas de 7 a 11 de setembro de 1909. A primeira versava sobre Breuer como fundador da psicanálise e o caso Anna O. ${ }^{4}$ A segunda palestra tinha como tema a contradição na teoria da histeria de Pierre Janet. Na terceira, ele apresentou sua teoria da interpretação dos sonhos. A quarta discutiu a sexualidade infantil, com a descrição do caso Pequeno Hans, referindo-se, também, ao caso Pequena Anna, estudado por Jung. A quinta e última palestra teve como tema os aspectos sociais

1 Foram convidados também o filósofo John Dewey e o psicólogo Wilhelm Wundt, que não puderam comparecer.

2 A biografia, Freud: uma vida para o nosso tempo, escrita por Gay (1995), diz que Freud, Jung e Ferenzci se encontraram em Bremen no dia 20 de agosto, partindo posteriormente para a América. Já Bair (2003), biógrafa de Jung, afirma que o trio teria combinado de se encontrar no dia 21 de agosto, data de partida do navio.

3 O médico Abraham Arden Brill estudou no Hospital Burghölzli, na Suíça, mas residia em Nova Iorque desde 1889. Posteriormente, foi o responsável pela tradução das obras de Freud para a língua inglesa (Taylor, 1999).

4 Em uma edição de 1924 dessa palestra, Freud retira a referência a Breuer como fundador da psicanálise, atribuindo todos os méritos da formação da nova teoria ao seu trabalho (Bair, 2003). 
e culturais da sexualidade na sociedade civilizada (Bair, 2003).

Jung apresentou três palestras, de 9 a 11 de setembro. A primeira teve como título $O$ método das associaçôes (Jung, 1908), na qual abordou os fundamentos de seu teste de associação de palavras. Trata-se, basicamente, de uma lista de palavras indutoras apresentadas a um sujeito experimental que deveria responder, o mais rápido possível, a cada item da lista, com a primeira palavra que lhe viesse à cabeça. O experimentador avaliava o tempo de resposta para cada palavra, assim como a natureza desta. A avaliação era aparentemente simples, mas revelava os conflitos emocionais do sujeito, pois as palavras com forte carga afetiva demandavam um tempo maior de resposta, e estas podiam ser correlacionadas entre si. A partir dessas experiências, Jung propôs a noção de complexo ideoafetivo ou, simplesmente, complexo, como associações de ideias com grande carga emocional. A segunda palestra teve como tema um trabalho orientado por Jung e desenvolvido pela doutora Emma Fürst, ${ }^{5}$ no Hospital Burghölzli, sobre os complexos familiares, tendo como título A constelação familiar (Jung, 1907). Ajustando-se às diretrizes de Hall, na terceira palestra, foram apresentadas as observações e análises do caso de uma menina de 4 anos, que, diante do nascimento de seu irmão, passou a ter medo de perder a mãe e a perguntar aos pais e familiares a respeito do nascimento e da morte. $\mathrm{Na}$ verdade, sob o nome de Anna, Jung apresentou o caso de sua filha Agathe, na época do nascimento de seu filho Franz. As palestras de todos os participantes foram publicadas no American Journal of Psychology de abril de 1910 e em Lectures and Addresses Before the Departaments of Psychology and Pedagogy, organizado por Hall, também em $1910^{6}$ (Bair, 2003; Jung, 1908; Jung, 1910; Koelsch, 1984).

Nesse período, William James já era considerado um dos mais importantes filósofos e psicólogos americanos. Ele compareceu à conferência em Clark, reservando um dia para assistir a uma das palestras de Freud, além de ter conversas reservadas com Freud e Jung. ${ }^{7} \mathrm{O}$ pensador americano acreditava que as ideias de Freud e seus colaboradores poderiam trazer importantes esclarecimentos sobre a natureza humana. Freud, no entanto, pareceu-lhe um homem de ideias fixas, principalmente em suas críticas à religião. William James expressou seu incômodo em relação à ortodoxia de Freud em carta a Theodore Flournoy (Barzun, 1983; James, 1920).

\footnotetext{
5 De acordo com Jung (1907, p. 517), "Emma Fürst, médica, membro da equipe da clínica psiquiátrica Burghölzli, da Universidade de Zurique. O título da publicação é Statistiche Untersuchungen über Wortassoziationen und über familiärie Übereinstimmung im Reaktionstypus bei ungebildeten".

6 A palestra "O método das associaçōes" de Jung (1908) foi publicada, pela primeira vez, no American Journal of Psychology, em 1910. O conteúdo da segunda palestra já havia sido publicado em 1907/1908 com o título Associations d’ideés familiale, no Archives de Psychologie. A terceira, além de ser publicada em 1910 no American Journal of Psychology, no mesmo ano, aparece no Jarbuch für psychoanalytische und psychopathologische Forchungen II. As apresentações de Jung em Clark também estão transcritas em suas Obras completas (Jung, 2011). A primeira e a segunda correspondem aos capítulos X e XI do livro Estudos experimentais. A terceira faz parte do livro $O$ desenvolvimento da personalidade, capítulo I.

7 Jung retornou aos Estados Unidos em 1910, quando teve sua segunda conversa com William James (Bair, 2003).
} 
Em relaçãoa Jung, James se mostrou bastanteimpressionado, poisos dois autores concordavam sobre a importância do fenômeno religioso para a psique humana. Conversaram de maneira reservada na casa de Hall. Jung estava particularmente interessado nas pesquisas de James sobre os chamados fenômenos psíquicos, especialmente sobre a médium Leonora Piper. Esses assuntos já ocupavam as pesquisas de James havia algum tempo e foram desenvolvidos, especialmente, em suas Gifford lectures. As impressões de Jung também foram positivas. Em suas Cartas, afirma que James foi uma das figuras mais impressionantes que conheceu em sua vida, admirando a sua abertura de visão e a maneira como, em suas pesquisas, deixava que os fenômenos se apresentassem espontaneamente, sem forçar uma interpretação para uma direção determinada (Jung, 1973).

Antes do encontro na Universidade Clark, Jung já havia entrado em contato com importantes obras de James, como The principles of Psychology (1890b), que utilizou como referência em seu trabalho de conclusão do curso de Medicina no ano de 1902. Na referida conferência, os dois autores conversaram sobre assuntos que não estavam na pauta das palestras, como parapsicologia, espiritualismo e curas pela fé, assuntos de interesse do psiquiatra suíço que não encontravam ressonância em Freud. Portanto, a partir do encontro entre os dois autores, desencadeou-se um processo, com efeitos importantes no trabalho de Jung, culminando com o seu afastamento do círculo psicanalítico no ano de 1913 e a construção de uma teoria própria: a Psicologia analítica (Shamdasani, 2003).

\section{REPERCUSSÕES DA TEORIA JAMESEANA SOBRE A OBRA DE C. G. JUNG}

As repercussões da teoria de William James sobre a obra de Carl Gustav Jung podem ser avaliadas pelo estudo das Obras completas do autor suíço (Jung, 2011). Encontramos referências ao pensador americano nas mais diversas pesquisas de Jung. Como primeiro ponto, destacamos os estudos psiquiátricos de Jung, que encontram uma nova perspectiva a partir dos trabalhos de James, em seguida, elaboramos como o pragmatismo, a tipologia e o pluralismo vão influenciar de maneira essencial os principais trabalhos do psiquiatra suíço. Da mesma forma, o conceito de inconsciente em Jung está associado a termos próprios da teoria de William James. Ainda destacamos o estudo da teoria das emoções e a avaliação acerca da experiência religiosa. Dessa forma, procuramos demonstrar os efeitos mais representativos engendrados na obra de Jung com base em sua leitura de James.

Já em seu primeiro trabalho, intitulado Sobre a psicologia e patologia dos fenômenos chamados ocultos (Jung, 1902), encontramos referências a William 
James acerca dos estudos do pensador americano sobre os estados alterados de consciência, especialmente em The principles of Psychology (James, 1890b). Jung (1902) nomeia esses fenômenos de "estados raros da consciência" (p. 13), sobre os quais as autoridades da psiquiatria, em sua época, ainda não haviam chegado a um acordo sobre sua origem e definição. As mais diversas classificações eram utilizadas, na busca por determinar esses eventos excepcionais da mente. Nomes como automatismo, letargia, amnésia periódica, dupla consciência, sonambulismo, entre outros, eram comuns na avaliação e descrição dos casos em estudo.

Esse trabalho trata-se da dissertação de Jung apresentada à Universidade de Zurique, para obtenção do título de médico. O psiquiatra suíço tem como objeto de pesquisa uma jovem descrita como médium, com a idade de 15 anos, identificada como S.W., a qual ele acompanhou em sessóes espíritas, no período de 1899 a 1900. Jung (1902) considerou os poderes psíquicos apresentados pela jovem como provenientes de estados psicológicos de sua mente e não de uma fonte sobrenatural, definindo S.W. como portadora de um estado de sonambulismo com carga hereditária.

Para chegar a essa conclusão diversos trabalhos foram utilizados. Dentre a extensa lista de autores e obras, destacamos o trabalho de James (1890b), The principles of Psychology, utilizado em dois momentos. A primeira referência se encontra em um estudo introdutório realizado por Jung (1902), de um caso de histeria com amnésia periódica, atendido no Hospital Burghözli, no qual Jung clinicava. Contribuições da literatura especializada são utilizadas na avaliação, como o caso descrito por James (1890a) sobre Ansel Bourne, de 30 anos. Após uma conversão súbita do ateísmo para o cristianismo, Bourne se tornou reverendo e pregador itinerante. No entanto, apresentava, com frequência, ataques de perda da consciência. Em uma crise, chegou a ficar desaparecido por dois meses, período durante o qual mudou de profissão e adotou o nome de A. J. Brow. Ao sair do estado de amnésia total, retornou para sua casa, em Greene, Estado de Rhode Island, nos Estados Unidos.

Outro estado raro de consciência descrito por Jung (1902) é o de Mary Reynolds, definido como mudança espontânea de caráter. Essa jovem senhora, moradora do Estado da Pensilvânia, após um sono profundo de 20 horas, apresentou uma mudança completa de sua personalidade. $\mathrm{O}$ caso foi estudado pelo médico Silas Weir Mitchell, que o definiu como de dupla consciência. Esse relato foi amplamente comentado por James (1890b). 


\section{ESTUDOS PSIQUIÁTRICOS}

$\mathrm{Na}$ fase inicial dos estudos de Jung, notamos uma presença marcante de explicações fisiológicas e referências psiquiátricas, que seriam revistas em momentos posteriores de sua obra. Na época em que o trabalho citado foi escrito, três personalidades eram destacadas como influentes no modelo de psiquiatria seguido por Jung: Pierre Janet, com quem o autor suíço estudou no ano de 1902, acompanhando seus cursos no Collège de France e suas experiências no Hôpital Salpêtrière; Eugen Bleuler, diretor do Hospital Burghözli, com quem Jung trabalhou de 1900 a 1909; e Sigmund Freud, tendo contato com a obra em 1900 e pessoal em 1907, quando iniciaram a parceria teórica (Bair, 2003).

A referência a William James se intensifica em estudos posteriores, demonstrando uma revisão de Jung do seu modelo psiquiátrico, pois James (1890a; 1890b) não traçava limites rígidos entre os fenômenos da consciência descritos como patológicos dos estados considerados normais. Em dois estudos, O conteúdo da psicose (Jung, 1914) e A esquizofrenia (Jung, 1958), ele destaca o conceito jameseano de fringe of consciousness. O primeiro trabalho foi escrito em 1908 e ampliado em 1914, quando incluiu uma interpretação psicológica dos processos patológicos. Utilizando como suporte o estudo de James (1907b) sobre tipologias, procurou demonstrar a necessidade de uma interpretação construtiva, ou compreensão prospectiva, buscando o que há de singular nos distúrbios psíquicos. A proposição básica é a seguinte: por mais que manifestações como a neurose e a psicose apresentem características gerais, o psicólogo também deveria buscar o que o indivíduo imprime de pessoal em sua doença mental, ou seja, a marca de seu temperamento, com o qual o terapeuta encontraria as vias de acesso para o desenvolvimento do tratamento. No segundo trabalho, Jung apresentou suas ideias sobre o surgimento dos delírios em casos de esquizofrenia. Em seu entendimento, trata-se de uma fragmentação da percepção, como descrito nos casos extremos de abaissement du niveau mental, de Janet (1889). Pela queda do limiar da consciência, o indivíduo entraria em contato com os conteúdos do inconsciente, algo semelhante ao que James (1890a; 1890b) descreve por meio de seu conceito de fringe of consciousness.

Podemos, então, destacar o nome de William James como referência nas pesquisas psiquiátricas de Jung, relacionando-o ao lado da tríade já mencionada: Janet, Bleuler e Freud. Ao relativizar o modelo médico, Jung (1936a) busca novas fontes teóricas, encontrando-as em Flournoy e em James:

A descrição biográfica do fenômeno anímico, ultrapassando o campo estritamente médico, era representado pela obra principal do filósofo Theodore Flournoy, de Genebra, ou seja, no concernente à psicologia de uma personalidade excepcional. 
Seguiu-se a ele uma primeira tentativa abrangente: a obra principal de William James, Varieties of Religious Experience (1902). Devo a esses dois investigadores ter compreendido a natureza do distúrbio psíquico no âmbito da alma humana em seu todo (Jung, 1936a, p. 64).

Para o psiquiatra suíço, a Psicologia deveria se aproximar do mundo e dos indivíduos. A esse movimento em direção à valorização da experiência subjetiva ele designou de compreensão do psíquico no âmbito da alma. No entanto, os estudos de Jung acerca das obras e teorias de James não se limitaram a pesquisas psiquiátricas, mas abrangeram um número muito maior de fatores. Em relação ao pragmatismo e à tipologia, vamos encontrar no trabalho $O$ problema dos tipos de atitude (Jung, 1912) uma primeira tentativa para desenvolver sua interpretação da teoria tipológica de James, presente na obra Pragmatism.

\section{PRAGMATISMO, PLURALISMO E TIPOLOGIA}

Uma das propostas iniciais do Pragmatism de James (1907b) é que a História da Filosofia é, na verdade, uma colisão de temperamentos humanos. As diferentes posturas filosóficas corresponderiam a visões pessoais. Ao elaborar seu sistema explicativo, o filósofo adaptaria a realidade a seu próprio modo. O temperamento seria a base das diferentes ideologias, o que poderia ser estendido para os campos da política, da literatura, das artes, da religião, da ciência, enfim, a todas expressões humanas. Especificamente em Filosofia, duas posturas opostas e fundamentais estariam em constante discussão: os racionalistas, defensores dos princípios abstratos e eternos; e os empiristas, adeptos dos fatos em toda a sua objetividade.

Os racionalistas são descritos, ainda, como espíritos ternos (tender-minded), enquanto os empíricos são definidos como espíritos duros (tough-minded). Há uma rivalidade entre esses dois tipos, que disputam a primazia da verdade. A atmosfera tumultuada do campo da Filosofia seria um reflexo desse conflito. Para Jung (1912), a existência de posicionamentos opostos faria parte do fluxo natural da vida. As diferentes visões dos indivíduos teriam funções compensatórias, permitindo a explicação da realidade sob perspectivas variadas. O que James (1907b) nomeia de tender-minded e tough-minded em Filosofia, de acordo com a explicação psicológica de Jung (1912), seria o mesmo que introvertido e extrovertido.

A referência ao tema continua nos prefácios a Collected Papers on Analytical Psychology, em que Jung (1916a) busca aplicar sua teoria tipológica desenvolvida a partir da Filosofia pragmática de James. Nessa visão, a Psicologia seria um campo onde diferentes posicionamentos também disputam espaço, como o 
caso das teorias de Freud e Adler. Para que possamos compreender a discussão proposta por Jung (1916a), é importante uma definição do que o autor entende por introvertido e extrovertido. No primeiro caso, o interesse do indivíduo é direcionado para ele mesmo, ou seja, a energia psíquica apresenta um movimento centrípeto de interiorização. Já, no segundo caso, os interesses pessoais são direcionados para os objetos externos e a energia psíquica tem um direcionamento centrífugo, que determina uma busca pelo mundo exterior. As duas tendências existem em todas as pessoas, no entanto, na formação da personalidade, uma das tendências assume a posição consciente, enquanto a outra, não desenvolvida, permanece inconsciente. $\mathrm{Na}$ aplicação dessas ideias à Psicologia, Freud, descrito por Jung como extrovertido, constrói sua teoria a partir da valorização do mundo externo, pois os indivíduos são analisados em sua busca constante por objetos capazes de satisfazer seus desejos. Adler, por sua vez, seria de tipo introvertido, dado que o foco de sua atenção é o sujeito em busca de autoexpressão e poder.

Um estudo mais detalhado da Filosofia pragmática de James é encontrado no livro Tipos psicológicos de Jung (1921), especialmente no capítulo O problema dos tipos na Filosofia moderna. O autor suíço parte da proposta inicial de James, a diversidade de posicionamentos, resumidos na dualidade racionalistas/empiristas. O pragmatismo se apresenta como a solução para o problema dos antagonismos teóricos, assim como a verdade passaria a ser um problema de aplicação.

Para James (1907a), as diferentes perspectivas teóricas se manifestariam na dissociação vivenciada pelo homem moderno. O progresso da ciência representaria o avanço do positivismo e do naturalismo, o alargamento do universo material e a diminuição da importância atribuída ao homem. Os ideais seriam o resultado da especulação prática e objetiva. A observação e a pesquisa fisiológica seriam as únicas fontes de informação para o puro empirismo. Por outro lado, a Filosofia religiosa estaria cada vez mais distante do contato com o mundo, com a objetividade se refugiando em um plano idealizado. Os filósofos mais abstratos, assim como os religiosos, formulariam sistemas que não corresponderiam à realidade, não entrando em contato com os problemas mais manifestos do homem.

Seria necessária, portanto, uma filosofia que estabelecesse alguma conexão com a vida, mas também que exercitasse as capacidades intelectuais de abstração, ou seja, um sistema que pudesse satisfazer as diferentes necessidades humanas, para a análise de fatos, exemplificada pela ciência, como pelo cultivo de valores humanos, como prega a religiáo. O que James (1907b) oferece como solução é o pragmatismo, entendido como método que busca interpretar cada noção, conceito ou teoria, traçando as suas consequências práticas. $\mathrm{O}$ pragmatismo seria capaz de encerrar as contendas filosóficas pelo simples fato de buscar as consequências empíricas das ideias. 
A filosofia de James serve de base para a teoria que Jung já desenvolvia, como pode ser verificado em suas cartas a Hans Schmid-Guisan, no ano de 1915 (Beebe \& Falzeder, 2013). Em Tipos psicológicos (Jung, 1921), o psiquiatra suíço apresenta sua teoria pluralista da Psicologia, demonstrando como as diferentes áreas do conhecimento humano, como artes plásticas, literatura, filosofia, religião, entre outras, não são uniformes, mas representam a própria diversidade humana.

$\mathrm{Na}$ conclusão do capítulo O problema dos tipos na Filosofia moderna, Jung (1921, p. 333) destaca a coerência do método pragmático, mas apresenta, da mesma forma, suas críticas: "James tem o grande mérito de ter apontado, pela primeira vez e com certa profundidade, para a extraordinária importância dos temperamentos na formação do pensamento filosófico". No entanto, também completa que a solução do conflito entre opostos não se dá por um compromisso lógico-intelectualista nem pela medição pragmática de concepções inconciliáveis. Os opostos deveriam ser vistos como elementos necessários de coordenação.

Apesar das críticas, o posicionamento de Jung em relação ao pragmatismo é considerado favorável. A teoria pragmática não teria sido abandonada, mas adaptada à proposta analítica de Jung. Mesmo sem usar o termo diretamente, as referências ao trabalho de James continuam ao longo de toda a obra do psiquiatra suíço. Por exemplo, em Os objetivos da psicoterapia, Jung (1929) adota o pragmatismo como eixo de sua conduta terapêutica, descrevendo o campo prático da Psicologia como fragmentado e formado por uma pluralidade de opiniões contraditórias. Assim, a validade das teorias somente poderia ser definida pelos resultados objetivos alcançados na prática clínica.

A partir dessa formulação, Jung (1929) determina a diversidade de tipos humanos e, por consequência, a diversidade de sistemas capazes de explicar a realidade. O pluralismo conceitual que acompanha o pragmatismo deveria ser o elemento norteador da Psicologia. No apêndice do texto $A$ estrutura do inconsciente, Jung (1916b) já defendia o papel da Psicologia como ciência plural:

A psicologia terá que adaptar-se ao reconhecimento de um pluralismo de princípio, embora isso não agrade muito ao espírito científico. Este é o único caminho que evitará o impasse da psicologia. Neste particular, a psicologia deve muito ao trabalho precursor de William James (p. 161).

A defesa do pluralismo também é encontrada em Determinantes psicológicas do comportamento humano, no qual Jung (1936c) busca demonstrar as funções perceptivas da psique. Em sua relação com o mundo, o indivíduo teria determinadas funções para a assimilação das experiências. A função sensação 
seria definida pelos sentidos físicos (visão, audição, olfato, tato, paladar), a partir dos quais a psique estabelecesse um primeiro contato com a realidade, sendo elaborada uma descrição interna do que é experimentado por meio da função pensamento. Por meio da determinação de valor do que é vivido e internalizado, a função sentimento imprime a diferenciação entre o que é bom e ruim. Todas essas experiências estão localizadas no tempo e no espaço, no entanto a função intuição delineia a existência de aspectos subliminais. Em seu processo adaptativo, os seres humanos utilizariam esses recursos de formas variadas; em algumas, o pensamento se torna mais desenvolvido, em outras, o sentimento, e assim por diante.

Essa variedade de possibilidades nos modos de ser do homem demonstra a complexidade da fenomenologia do psíquico. As tentativas por elaborar uma teoria abrangente que defina o homem de forma absoluta estão, de acordo com Jung (1936c), condenadas ao fracasso, porque contêm a ilusão de simplificar a diversidade. Na concepção junguiana, a psique é o ponto de partida e de chegada de todas as experiências humanas e, em Psicologia, ela é o sujeito e o objeto da ciência. Essa posição singular a coloca diante de um problema de difícil resposta: como construir uma ciência a partir da diversidade e das particularidades da condição humana, se a ciência clássica só se ocupa de aspectos universais, gerais e objetivos?

Jung teria encontrado no pluralismo de James a resposta para essa questão, pois, mesmo as Ciências Exatas teriam como pano de fundo um fator subjetivo. O homem imprimiria suas particularidades em todas as suas manifestações, inclusive na ciência. Esse elemento pessoal tornar-se-ia ainda mais expressivo em relação à Ciência Psicológica, na qual uma objetividade absoluta não seria possível, pois a Psicologia teria por característica fundamental o pluralismo conceitual. Sobre a necessidade de uma Psicologia pluralista, Jung (1936c) afirma:

Neste meu breve - quiçá demasiado breve - esboço, deixei de mencionar muitos nomes ilustres, mas há um nome venerável que não quero omitir: é o de William James, a cuja visão psicológica e a cuja filosofia pragmática devo os mais decisivos estímulos e sugestôes em minhas pesquisas. Foi seu espírito largo e abrangente que me descerrou até o incomensurável os horizontes da psicologia humana (p. 71).

\section{A TEORIA DO INCONSCIENTE}

Outro ponto essencial para a compreensão da Psicologia analítica é o conceito de inconsciente, que, na obra de Jung, encontra-se entrelaçado ao trabalho de William James, da mesma forma que a compreensão do distúrbio psíquico, do 
pragmatismo, do pluralismo e da tipologia já destacados. O posicionamento de Jung se apresenta, no entanto, ambivalente, ora considerando o inconsciente como muito mais amplo e complexo do que James descreve (Jung, 1934), ora afirmando que o limiar de acesso ao inconsciente é a fringe of consciousness de James (Jung, 1946).

Como as afirmações de 1946 se encontram mais elaboradas, vamos tomá-las como base para determinar o lugar das teorias de James em relação ao inconsciente proposto pelo autor suíço. Nas afirmações de Jung (1946), a descoberta de uma psique inconsciente foi fator que revolucionou a Psicologia, da mesma forma que a radioatividade revolucionou a física. A referência à descoberta se encontra no The varieties of religious experience, quando James (1902) aponta Frederic Myers como o primeiro a formular o conceito de subliminal, revelando, dessa forma, aspectos insuspeitos da natureza humana. A consciência de vigília, com seu centro e margens habituais, seria apenas uma parte da mente. Para além das bordas da consciência, com seus fatos cotidianos, existiriam recordações, sentimentos e pensamentos com certa independência e capazes de revelar sua presença por meio de sinais inequívocos.

Jung (1946) ainda destaca os conceitos jameseanos de fringe of consciousness, field of consciousness, bursting point e transmarginal field em suas explicaçôes acerca do tema. Um fato importante sobre o conceito de field of consciousness é que o campo representaria um agregado de ideias, pensamentos e sentimentos que constituiriam o estado de vigília do indivíduo. Para além das margens desse estado consciente, existiria todo um acervo de recordações, impulsos e potencialidades, ou seja, outros campos conscientes, demonstrando que a individualidade não é única, mas plural em sua própria vida psíquica. $\mathrm{O}$ conjunto total desses conteúdos, forças e conhecimentos residuais constituiriam o self empírico de James (1902). Para o filósofo americano, a região inexplorada, chamada genericamente de subconsciente, teria toda espécie de matéria e não apenas desejos reprimidos e memórias perdidas. Essas afirmações vêm ao encontro do que Jung (1946) procurava demonstrar em relação ao inconsciente.

O último trabalho escrito por Jung (1961), Símbolos e interpretação dos sonhos, reforça a importância de William James para compreensão dos aspectos inconscientes da psique, pois a fringe of consciousness é definida como o limiar de acesso ao inconsciente, conferindo cor ao mundo pelo processo de associação.

\section{TEORIA DAS EMOÇÕES}

Outro tema de conexão entre as obras de Jung e de William James diz respeito à teoria das emoções. A proposta de James foi apresentada simultaneamente à do fisiólogo dinamarquês C. G. Lange, ficando conhecida como teoria James- 
Lange. Em conferências na Clínica Tavistok, de Londres, que deram origem ao livro Fundamentos de Psicologia analitica, Jung (1935) fez menção a essa teoria quando apresentou o seu método clínico. Inicialmente, Jung expôs seus comentários acerca da relação entre consciente e inconsciente, assim como as funçôes ectopsíquicas: pensamento, sentimento, sensação e intuição. Durante o debate, o Dr. J. A. Hadfield perguntou em que sentido Jung utilizou a palavra "emoção", quando explicava a função sentimento: sentimento e emoção seriam a mesma coisa para a Psicologia analítica? Jung destacou a relevância da pergunta e afirmou que a base de seu entendimento sobre a emoção se encontrava em William James. Segundo James (1890b), o organismo é como uma caixa de ressonância, que responde às mudanças e alterações mais sutis por meio de mecanismos organizados. Assim, qualquer manifestação emocional seria o resultado de uma reverberação corporal. O complexo sistema emocional acionaria as mais diversas partes do corpo, sendo imenso o número de partes modificadas em cada emoção, o que torna difícil a reprodução integral de uma emoção a sangue frio.

A explicação de James (1890b) é clara e objetiva: se quisermos lembrar de alguma emoção forte e, nesse processo, afastar o elemento corporal, perceberemos que nada resta. Não existe medo sem o coração disparado, os lábios trêmulos, as pernas dormentes, a pele arrepiada e o estômago embrulhado, ou raiva sem a sensação de agitação no peito, o rosto vermelho, as narinas dilatadas e os dentes pressionados. Cada uma das alterações corporais é sentida de forma aguda no momento emocional, ou seja, a mais leve emoção desperta alterações corporais.

Baseado nessa referência, Jung (1935) estabelece que as emoções seriam caracterizadas por inervações fisiológicas, uma condição física, tangível e observável pelas alteraçôes que provoca no corpo. Já o sentimento seria uma função valorativa, racional, que distingue o que nos agrada do que nos desagrada. A emoção seria como uma força que arrasta o indivíduo para além de sua vontade, sendo extremamente difícil controlar as reações que desperta. O sentimento seria uma função cognitiva, e o indivíduo estaria no controle. No entanto, como afirma Jung, a distinção entre sentimento e emoção poderia ser simplificada por meio da questão da intensidade:

O problema está apenas numa questão de grau. Se houver um valor obsessivamente forte, sua tendência é tornar-se emoção num dado momento, ou seja, quando atingir a intensidade suficiente para causar uma inervação fisiológica. Todo processo mental provavelmente cause ligeiras inervações desse tipo, e são realmente tão pequenas que não há meios de demonstrá-las. Existe, entretanto, um método bastante sensível de registrar as emoções em suas manifestações fisiológicas; trata-se do efeito psicogalvânico (p. 40). 
O debate sobre as emoções seguiu-se com o Dr. B. D. Hendy perguntando a Jung se a emoção seria, então, causa ou efeito da reação fisiológica. Ao que Jung respondeu, de acordo com o The principles of Psychology de James, que a emoção é a consequência, não a causa da expressão corporal. No entanto o problema suscitou questóes interessantes acerca da relação mente-corpo que, segundo Jung (1935), seriam respondidas pelos diferentes teóricos, segundo seu caráter e temperamento. Para alguns indivíduos, que admitem a supremacia do corpo, a mente seria um epifenômeno da química cerebral. Outros, no entanto, adotam a tese contrária, sendo a mente a origem de todos os processos que se desenrolam no cérebro. De acordo com Jung, tudo o que é possível observar empiricamente é a simultaneidade no desenrolar dos processos corporais e mentais.

\section{EXPERIÊNCIA RELIGIOSA}

Para James (1902, p. 39), a experiência religiosa era, antes de tudo, uma experiência humana: "Religion, whatever it is, is a man's total reaction upon life, so why not say that any total reaction upon life is a religion?". ${ }^{8} \mathrm{Em}$ seu livro The varieties of religious experience, James apresenta diferentes tópicos, como a relação entre neurologia e religião, a realidade de eventos não tangíveis, os processos de conversão, a santidade, o misticismo, entre outros. Além disso, busca destacar aspectos psicológicos associados à religiosidade: fatores emocionais, diversidade de experiências e papel do subconsciente, que perpassam os diferentes relatos. $\mathrm{O}$ livro versa sobre a experiência religiosa, mas os objetivos do projeto de psicologia de James aparecem como norteadores de sua avaliação do fenômeno.

Compreendendo esse elemento marcante do pensamento de James, em suas obras, Jung destaca os relatos das experiências religiosas em seus diferentes aspectos. Algumas vezes, enfatizando os elementos psicológicos da experiência, como uma forma de acesso ao inconsciente, como em $O$ arquétipo como referência especial ao conceito de anima (1936b), Determinantes psicológicas do comportamento humano (1936c) e Consideraçôes teóricas sobre a natureza do psíquico (1946). Em outros momentos, o destaque recai sobre o contato com o divino, como no livro Psicologia e religião (1939). No entanto, os dois elementos se encontram indissociados, participando, da mesma forma que em James, do seu modelo de Psicologia.

De acordo com James (1902), as propensões religiosas do homem são importantes fatores de sua constituição mental, sendo de fundamental interesse, não as instituições religiosas, mas os sentimentos religiosos e os impulsos a eles associados, que são vivenciados de maneira significativa e como se fossem

8 "A religião, seja ela qual for, é a reação total de um homem à vida, portanto, porque não dizer que qualquer reação total à vida é uma religião?” (Tradução nossa). 
uma experiência direta dos sentidos. $O$ pensador americano afirma que não se alcança a verdade na esfera religiosa com base em argumentos lógicos, mas em nível intuitivo, que dificilmente é abalado pela compreensão intelectualista. Da mesma forma, em Psicologia e religiāo, Jung (1939) tenta demonstrar como a manifestação de elementos religiosos faz parte de um processo natural da psique humana.

Nas perspectivas de James e de Jung, em relação aos aspectos religiosos, o que interessa ao psicólogo é a experiência original, que tem como foco a vivência humana. Assim, a experiência religiosa não estaria restrita às instituições e nem a certos homens especiais, mas se manifestaria por meio de diversas pessoas, em todas as épocas e culturas, sendo elemento comum do psiquismo. Dessa forma, os dois autores permitem um estudo das bases a partir das quais se viabiliza a qualificação dessa experiência fundamental.

\section{CONSIDERAÇÕES FINAIS}

Jung se encontrou a primeira vez com James em 1909, mas o contato teórico entre os dois autores não foi longo, devido ao falecimento de James, em 1910. No entanto o psiquiatra suíço encontrou estímulo para aprofundar suas pesquisas acerca da teoria complexa do pensador americano. Pela pesquisa de suas Obras completas (Jung, 2011), notamos que Jung avaliou aspectos importantes da teoria jameseana, como pesquisa psíquica e psiquiátrica, pragmatismo, tipologia, pluralismo, teoria das emoçóes e experiência religiosa. Do amplo espectro de efeitos da obra de James sobre a Psicologia analítica de Jung, o aspecto religioso se destaca. Por esses estudos, o pensador americano desenvolveu importantes elementos de sua Psicologia subliminal. As impressóes de James sobre as experiências religiosas, alguns meses antes de sua morte, reforçam sua posição de que o subconsciente estava envolvido nesses processos, o que levava ao conhecimento de que sentimentos, pensamentos e imagens não se encontravam em sua totalidade na consciência de vigília. A mente deveria ser avaliada em sua extensão, não somente o que flutuava na superfície, mas também o submerso. O exame atento do tema deveria ter por norte o subliminar. Essa afirmação deixa em suspenso a negação ou a afirmação acerca das realidades religiosas. Atesta apenas que os eventos tinham seu surgimento e desenvolvimento pela via subconsciente (Taylor, 1999).

Jung tinha interesse na temática religiosa muito tempo antes de seu encontro com James. Em seu artigo Sobre ocultismo (1905), Jung afirma que teria desenvolvido pesquisas com oito médiuns, 6 mulheres e 2 homens, sendo uma delas provavelmente sua prima Helene Preiswerk. Afirma que o interesse maior 
dessas pesquisas se limitava aos aspectos psicológicos. Em alguns casos, os relatos desafiavam a capacidade de compressão e seriam alvo de um ceticismo natural, por parte daqueles que não eram testemunhas oculares dos fenômenos. Em relação a suas leituras, muitas das descrições que havia consultado permaneciam como enigmas psicológicos não resolvidos, no entanto ele reconhecia a necessidade das pessoas de "emoçôes oceânicas" (Jung, 1905, p. 313), ou seja, um desejo pela imortalidade, que seria oferecida pelas visões de sonâmbulos, médiuns e religiosos. $\mathrm{O}$ encontro com James foi a oportunidade de compartilhar seus interesses e encontrar estímulo para suas pesquisas. $\mathrm{O}$ filósofo americano passou a ser um modelo para Jung, em sua abertura de visão e coragem de avaliar os fenômenos mais controversos. 


\section{REFERÊNCIAS}

Bair, D. (2003). Jung: uma biografia (Vol. 1). São Paulo: Globo.

Barzun, J. (1983). A stroll with William James. New York: Harper \& Row Publishers.

Beebe, J. \& Falzeder, E. (Eds.). (2013). The question of psychological types: the correspondence of C. G. Jung and Hans Schmid-Guisan, 1915-1916. Princeton: Princeton University Press.

Gay, P. (1995). Freud: uma vida para o nosso tempo. São Paulo: Companhia das Letras.

James, W. (1890a). The principles of Psychology. (Vol. 1). London: Forgotten Books, 2013.

James, W. (1890b). The principles of Psychology. (Vol. 2). London: Forgotten Books, 2013.

James, W. (1902). The varieties of religious experience: a study in human nature. New York: Library of America, 2010.

James, W. (1907a). Pragmatismo. São Paulo: Nova Cultural, 1989. (Coleção Os Pensadores).

James, W. (1907b). Pragmatism: a new name for some old ways of thinking. London: Forgotten Books, 2014.

James, W. (1920). The letters of William James. (Vol. 2). Boston: The Atlantic Monthly Press.

Janet, P. (1889). L'automatisme psychologique. Paris: Ancienne Librairie Germer Baillière.

Jung, C. G. (1902). Sobre a psicologia e patologia dos fenômenos chamados ocultos. In C. G. Jung Estudos Psiquiátricos. (Vol. 1, pp. 11-104). Petrópolis: Vozes, 2011.

Jung, C. G. (1905). Sobre ocultismo. In C. G. Jung A vida simbólica. (Vol. 18/1, pp. 311-350). Petrópolis: Vozes, 2012.

Jung, C. G. (1907). A constelação familiar. In C. G. Jung Estudos experimentais. (Vol. 2, pp. 517-530). Petrópolis: Vozes, 2012. 
Jung, C. G. (1908). O método das associações. In C. G. Jung Estudos experimentais. (Vol. 2, pp. 490- 516). Petrópolis: Vozes, 2012.

Jung, C. G. (1910). Sobre os conflitos da alma infantil. In C. G. Jung. O desenvolvimento da personalidade. (Vol. 17, pp. 17-47). Petrópolis: Vozes, 2012.

Jung, C. G. (1912). O problema dos tipos de atitude. In C. G. Jung. Psicologia do inconsciente (Vol. 7/1, pp. 52-74). Petrópolis: Vozes, 2011.

Jung, C. G. (1914). O conteúdo da psicose. In C. G. Jung. Psicogênese das doenças mentais (Vol. 3, pp. 173-216). Petrópolis: Vozes, 2011.

Jung, C. G. (1916a). Collected papers on analytical Psychology. In C. G. Jung. Freud e a psicanálise (Vol. 4, pp. 291-298). Petrópolis: Vozes, 2011.

Jung, C. G. (1916b). Apêndice. A estrutura do inconsciente. In C. G. Jung. O eu e o inconsciente (Vol. 7/2, pp. 133-170). Petrópolis: Vozes, 2011.

Jung, C. G. (1921). Tipos psicológicos (Vol. 6). Petrópolis: Vozes, 2011.

Jung, C. G. (1929). Os objetivos da psicoterapia. In C. G. Jung. A prática da psicoterapia (Vol. 16/1, pp. 48-65). Petrópolis: Vozes, 2011.

Jung, C. G. (1934). Considerações gerais sobre a teoria dos complexos. In C. G. Jung. A natureza da psique. (Vol. 8/2, pp. 39-52). Petrópolis: Vozes, 2011.

Jung, C. G. (1935). Fundamentos da Psicologia analítica. In C. G. Jung. A vida simbólica (Vol. 18/1, pp. 13-200). Petrópolis: Vozes, 2011.

Jung, C. G. (1936a). Os arquétipos e o inconsciente coletivo. (Vol. 9/1). Petrópolis: Vozes, 2012.

Jung, C. G. (1936b). O arquétipo como referência especial ao conceito de anima. In C. G. Jung. Os arquétipos e o inconsciente coletivo (Vol. 9/1, pp. 6381). Petrópolis: Vozes, 2012.

Jung, C. G. (1936c). Determinantes psicológicas do comportamento humano. In C. G. Jung. A natureza da psique. (Vol. 8/2, pp. 60-71). Petrópolis: Vozes, 2013.

Jung, C. G. (1939). Psicologia e religião. (Vol. 11/1). Petrópolis: Vozes, 2011.

Jung, C. G. (1946). Considerações teóricas sobre a natureza do psíquico. In C. G. Jung. A natureza da psique. (Vol. 8/2, pp. 104-185). Petrópolis: Vozes, 2011. 
Jung, C. G. (1958). A esquizofrenia. In C. G. Jung. Psicogênese das doenças mentais (Vol. 3, pp. 289-306). Petrópolis: Vozes, 2011.

Jung, C. G. (1961). Símbolos e interpretação dos sonhos. In C. G. Jung. A vida simbólica (Vol. 18/1, pp. 201-310). Petrópolis: Vozes, 2011.

Jung, C. G. (1973). Cartas de C. G. Jung. (Vol. 3). Petrópolis: Vozes, 2003.

Jung, C. G. (2011). Obras completas. Petrópolis: Vozes.

Koelsch, W. A. (1984). Incredible day dream: Freud and Jung at Clark, 1909. Worcester: Friends of the Goddard Library.

Richardson, R. D. (2006). William James: in the maelstrom of American modernism. Boston \& New York: Houghton Mifflin Company.

Sech, A. J., Araujo, S. F. \&, Moreira-Almeida, A. (2013). William James and psychical research: towards a radical science of mind. History of Psychiatry, 24, 62-78.

Shamdasani, S. (2003). Jung e a construção da Psicologia Moderna: o sonho de uma ciência. São Paulo: Ideias \& Letras.

Taylor, E. (1999). Shadow culture: Psychology and spirituality in America. Washington: Counterpoint. 